\title{
НОВАЯ АНАЛИТИЧЕСКАЯ СРЕДА НА ОСНОВЕ ПРОЗРАЧНОЙ ПОЛИМЕТИЛМЕТАКРИЛАТНОЙ МАТРИЦЫ ДЛЯ ТВЁРДОФАЗНОЙ СПЕКТРОФОТОМЕТРИИ
}

\author{
Гавриленко Н.А. ${ }^{1}$, Саранчина Н.В. $^{2}$, Гавриленко М.А. ${ }^{2}$
}

${ }^{1}$ Национальный исследовательский Томский государственный университет, Томск, Россия

${ }^{2}$ Национальный исследовательский Томский политехнический университет, Томск, Россия gavrilenko@mail.tsu.ru

DOI: 10.26902/ASFE-11_39

Сочетание спектрофотометрии и цветометрии с химическими оптическими сенсорами, которые обладают малым временем отклика и достаточной чувствительностью, дает возможность эффективно решать задачи аналитической химии в условиях, когда использование сложных инструментальных методов анализа затруднено вследствие сложной пробоподготовки, необходимости использования токсичных реагентов или привлечения квалифицированного персонала. Для оптических сенсоров особый интерес представляет прозрачная полиметакрилатная матрица (ПММ), в силу многообразия возможностей модифицирования и варьирования природы иммобилизованных соединений, что существенно улучшает характеристики методов молекулярной абсорбционной спектроскопии. Необходимое развитие использования ПММ требует разработки способов использования спектрофотометрических реагентов, выбора алгоритмов управления характеристиками новой аналитической среды, разработки рациональных вариантов сочетания способа определения с твердофазной экстракцией и выбором аналитического сигнала.

Изучены новые прозрачные аналитические системы на основе ПММ, используемой в качестве сенсора, путем исследования их цветометрических характеристик после проведения аналитической реакции для получения информации о количестве анализируемого вещества. Впервые создан комплекс методик определения ионов металлов, детектирования красителей в пищевых продуктах, антиоксидантов, витаминов, перекисных соединений, а также неорганических анионов на основе прозрачных полимерных сенсоров и исследованы закономерности изменения. Проведена оценка метрологических характеристик разработанных способов определения показана их перспективность в спектрофотометрическом и флуоресцентном методах анализа.

Использование прозрачной аналитической среды на основе ПММ включает использование сорбционных, экстракционных и хромогенных процессов и является перспективным направлением развития метода твердофазной молекулярной абсорбционной спектроскопии. Применение аналитической среды ПММ предоставляет широкие возможности управления характеристиками методик в части устойчивости окрашенных продуктов реакций, скорости их протекания, повышения метрологических характеристик оптических методов и делает анализ более мобильным и доказательным.

Основными направлениями использования ПММ для твердофазной молекулярной абсорбционной спектроскопии, визуальных и тест-методов анализа являются: изучение способов повышения чувствительности и селективности определения за счет выбора хромогенных реагентов и синтеза прозрачных полимерных матриц под конкретные аналитические задачи; расширение номенклатуры определяемых ионов и молекулярных веществ, преимущественно в области биологически активных веществ, т.е. витаминов, антиоксидантов, пестицидов и лекарственных препаратов; миниатюризация используемых приборов регистрации сигнала, комбинирование спектрофотометрического и колориметрического сигналов для повышения информативности анализа. 